\title{
Ocean-Warming During Embryogenesis Programs a Lasting Transcriptomic Signature in Fishes
}

\author{
Daniel M. Ripley ${ }^{1}$, Terence Garner ${ }^{2}$, Samantha A. Hook ${ }^{3}$ Ana Veríssimo ${ }^{4,5}$, Bianka Grunow 6 , Timo \\ Moritz $^{7,8}$, Peter Clayton ${ }^{2}$, Holly A. Shiels ${ }^{1}$, Adam Stevens ${ }^{2}$
}

\author{
1Division of Cardiovascular Sciences, Faculty of Biology, Medicine and Health, The University of \\ Manchester, Manchester, UK. \\ 2Division of Developmental Biology and Medicine, Faculty of Biology, Medicine, and Health, The \\ University of Manchester, Manchester, UK. \\ ${ }^{3}$ Department of Earth and Environmental Sciences, The University of Manchester, Manchester, UK. \\ ${ }^{4} \mathrm{CIBIO}$, Centro de Investigação em Biodiversidade e Recursos Genéticos, InBIO Laboratório \\ Associado, Campus de Vairão, Universidade do Porto, 4485-661 Vairão, Portugal \\ ${ }^{5} \mathrm{BIOPOLIS} \mathrm{Program} \mathrm{in} \mathrm{Genomics,} \mathrm{Biodiversity} \mathrm{and} \mathrm{Land} \mathrm{Planning,} \mathrm{CIBIO,} \mathrm{Campus} \mathrm{de} \mathrm{Vairão,} \mathrm{4485-}$ \\ 661 Vairão, Portugal \\ ${ }^{6}$ Institute of Muscle Biology and Growth, Research Institute for Farm Animal Biology, Wilhelm-Stahl- \\ Allee 2, 18196 Dummerstorf, Germany. \\ ${ }^{7}$ Deutsches Meeresmuseum, Katharinenberg 14-20, 18437 Stralsund, Germany \\ 8Institute of Biological Sciences, University of Rostock, Albert-Einstein-Straße 3, 18059 Rostock, \\ Germany
}

KEYWORDS climate change, long term effect, gene expression, plasticity, developmental programming, Scyliorhinus canicula, RNA-seq.

RUNNING HEADER Warming programs the transcriptome of fishes

\section{Abstract}

Exposure to elevated temperatures during embryogenesis has profound acute effects on the cardiac performance, metabolism, and growth of fishes. Some temperature-induced effects may be retained into, or manifest in, later-life through a mechanism termed developmental programming. In this study, we incubated Scyliorhinus canicula embryos at either $15^{\circ} \mathrm{C}$ or $20^{\circ} \mathrm{C}$ before transferring the newly hatched sharks to a common set of conditions $\left(15^{\circ} \mathrm{C}\right)$ for 5 months. Lasting transcriptomic differences associated with the developmental environment were identified, and interactions between cardiac genes were investigated using hypernetwork modelling. Development at an elevated temperature caused changes in transcriptomic connectivity and entropy, parameters thought to relate to plasticity and fitness. We then validated these observations through a novel re-analysis of published Danio rerio and Dicentrarchus labrax muscle tissue datasets. Together, these data demonstrate a persistent, programmed effect of developmental temperature on the co-ordination of gene expression in three species of fishes, which may relate to altered plasticity and fitness in later-life. 


\section{INTRODUCTION}

Developmental programming comprises changes to an organism's phenotype that are induced, or programmed, by the environmental conditions experienced during development (Bateson et al., 2014). These developmental conditions elicit changes in DNA and chromatin methylation patterns, with consequent alterations in gene expression (Fellous et al., 2015). Some of these changes in methylation pattern, and their concomitant influence on gene expression, can become fixed and retained into later life. For instance, changes in developmental temperature cause hypermethylation in threespine stickleback (Metzger \& Schulte, 2017), and studies in rainbow trout (Oncorhynchus mykiss) demonstrate the ability of early-life hypoxic events (Liu et al., 2017) and dietary composition (Geurden et al., 2014) to alter glucose metabolism and homeostasis in later-life. Finally, the developmental temperature of zebrafish (Danio rerio) has been shown to program their gene expression and physiology, culminating in an enhanced thermal tolerance (Schaefer \& Ryan, 2006) and acclimation capacity (Schnurr et al., 2014; Scott \& Johnston, 2012) in adulthood.

As well as altering mean trait values, the embryonic environment can also program an organism's ability to acclimate to conditions experienced in later-life (Beaman et al., 2016). That is, the capacity to physiologically respond to and mitigate future environmental challenges can be enhanced or hindered by an individual's embryonic conditions (Beaman et al., 2016). Evidence in zebrafish (Danio rerio) (Scott \& Johnston, 2012; Schnurr et al., 2014) and mosquitofish (Gambusia holbrooki) (Seebacher et al., 2014), amongst other species (Beaman et al., 2016), show that the thermal environment experienced during early-life can have lasting effects on the acclimation capacity of multiple physiological traits, including metabolic scope (Seebacher et al., 2014), critical thermal maximum (Healy et al., 2019), and swimming performance (Scott \& Johnston, 2012).

Phenotypic changes arising from physiological plasticity are underwritten by changes in an organism's gene expression in response to environmental cues. Such plasticity may be affected by an individual's embryonic environment, which may either facilitate or hinder changes in gene expression later in life (Beaman et al., 2016). Thus, there is a link between an organism's phenotype, gene expression, and plastic potential, which can be modulated by its embryonic environment (Beaman et al., 2016). Transcriptional entropy is a metric describing the order or predictability of gene-gene interactions within a transcriptional network. The more entropic a network, the less structured and less predictable its behaviour. Transcriptional entropy is known to correlate with the differentiation potency and phenotypic plasticity of single cells (Banerji et al., 2013; Teschendorff \& Enver, 2017). The more entropic a cell, the greater its number of possible fates (Teschendorff \& Enver, 2017), and thus the more plasticity it possesses. Given that several studies have shown that the environmental temperature experienced during development can alter plasticity in the adult organism (Beaman et al., 2016), we aimed to assess whether developmental temperature also alters gene-level plasticity by measuring the network entropy and connectivity of the transcriptome in later life.

Whilst many animals may experience adverse environmental conditions during embryogenesis, some species, owing to their ecology, are more prone than others. Oviparous elasmobranchs, because of their protracted, sessile developmental period, are susceptible to experiencing sub-optimal 
environmental conditions for long durations. Oviparous elasmobranchs lay their eggs inside collagenous egg cases termed mermaid's purses, which the embryo remains within for several months to over a year, depending on the species (Benjamins et al., 2021; McLaughin \& Ogower, 1971). Throughout embryogenesis the embryo is unable to move from, and thus may be consistently exposed to, unfavourable environmental conditions such as elevated temperatures. As the world's oceans continue to warm (IPCC, 2021), the likelihood of oviparous elasmobranch embryos developing in sub-optimal conditions is increasing. Representative pathway (RCP) 8.5, a worst-case scenario model, estimates a $\sim 3^{\circ} \mathrm{C}$ increase in ocean temperatures by the end of the century if greenhouse gas emissions continue to rise (Cai et al., 2014). The rising ocean temperatures, coupled with an increasing frequency and duration of marine heatwaves (Oliver et al., 2018), renders exposure to temperatures above animal's optima highly likely. Exposure to elevated temperatures is known to affect the growth and development of elasmobranch embryos (Hume, 2019; Musa et al., 2020; Rosa et al., 2014). However, no studies have investigated how embryogenesis at elevated temperatures may have lasting effects on elasmobranchs through developmental programming mechanisms.

Here, we incubate Scyliorhinus canicula embryos at $15^{\circ} \mathrm{C}$ or $20^{\circ} \mathrm{C}$ throughout embryogenesis before moving them to a common-garden environment $\left(15^{\circ} \mathrm{C}\right)$ upon hatching. Following 5 months in the common garden environment, we sacrificed the animals and performed RNA-seq on the ventricle tissue of six individuals to investigate whether the developmental environment could program lasting changes in the gene expression and organisation of the S. canicula ventricular transcriptome. Finally, to validate our findings, we re-analysed published datasets of temperature-induced developmental programming in zebrafish (Danio rerio) hypaxial fast muscle (Scott \& Johnston, 2012) and European seabass (Dicentrarchus labrax) muscle (Anastasiadi et al., 2021) to test the consistency of our observations across multiple species of fishes.

\section{MATERIAL AND METHODS}

\subsection{Experimental animals}

Scyliorhinus canicula embryos were collected from a population of 7 adult individuals held $15^{\circ} \mathrm{C}$ at the Ozeaneum, Stralsund, Germany, and transported to the University of Manchester, UK. Upon arrival the health and developmental stage of each embryo was assessed using the Musa scale (Musa et al., 2018), and the egg cases were submerged in dechlorinated tap water for two minutes to remove any marine microorganisms. Only healthy embryos at stage 1 were used in the study (Musa et al., 2018). All regulated procedures received approval from the institution's ethical review board.

Following embryonic staging and two days in quarantine $\left(15^{\circ} \mathrm{C}\right)$, individuals were randomly assigned to a temperature treatment group $\left(15 \pm 0.3^{\circ} \mathrm{C}\right.$ or $\left.20 \pm 0.3^{\circ} \mathrm{C}\right) .15^{\circ} \mathrm{C}$ was chosen for the control condition as it falls within the range of temperatures experienced by $S$. canicula in the wild and is the holding temperature of the parent population at the Ozeaneum, Stralsund, Germany. The egg cases in each treatment group were hung vertically in two, well aerated, 55 I static seawater (35ppt salinity) tanks equipped with internal filters and left to continue their embryonic development. 
117 Upon hatching, fin clips were taken to facilitate identification in later-life through microsatellite

118 analysis. The fin clips were stored in $98 \%$ ethanol at $-20^{\circ} \mathrm{C}$, and the sharks were moved into one of

119 four well aerated $400 \mathrm{I}$ static seawater tanks held at $15^{\circ} \mathrm{C} \pm 0.3^{\circ} \mathrm{C}$. The hatchlings from the $20^{\circ} \mathrm{C}$

120 treatment group were lowered to $15^{\circ} \mathrm{C}$ at a rate of $2.5^{\circ} \mathrm{C}$ per day, and sharks from both treatment

121 groups were mixed and randomly allocated to a tank. The sharks were fed a mixture of squid, crab

122 and krill three times per week. The sharks from both treatment groups were held at $15^{\circ} \mathrm{C} \pm 0.3^{\circ} \mathrm{C}$ for

123 an average of 136 days prior to tissue sampling. During the entire experiment, saltwater changes

124 were performed three times weekly to maintain ammonia, nitrite and nitrate below detectable levels.

\section{$125 \quad 2.2$ Tissue sampling}

126 Sharks at 4-5 months age (mean \pm SEM $=136 \pm 6$.3days) were euthanised with an overdose of

127 buffered tricane methanesulfonate and a fin clip was taken post-humous. The ventricle was excised

128 from each individual, placed into RNAlater, and flash frozen in liquid nitrogen before being stored at -

$12980^{\circ} \mathrm{C}$ prior to RNA-sequencing.

\section{$130 \quad 2.3$ Individual identification using microsatellite analysis}

131 To identify which condition an individual was developed in, microsatellite analysis was performed on

132 the fin clips taken at birth and at the end of the experiment to match each individual using the

133 methods described in Hook et al. (2019). Fin clips were extracted using a BioLine Isolate Genomic kit

134 with an extended proteinase $\mathrm{K}$ digestion to maximise DNA yield. DNA yield was assessed using a

135 NanoDrop ND-1000 spectrophotometer (Thermo Fisher Scientific, USA) and gel electrophoresis. A

136 one-primer cocktail containing 11 microsatellites and three tail dyes was used for DNA amplification

137 (Griffiths et al., 2011) using the QIAGEN multiplex PCR kit. The thermocycling protocol consisted of

138 initial denaturation cycle at $95^{\circ} \mathrm{C}$ for 15 minutes, followed by 35 cycles of $94^{\circ} \mathrm{C}$ for 30 seconds, $60^{\circ} \mathrm{C}$

139 for 90 seconds and $72^{\circ} \mathrm{C}$ for 45 seconds, and finalised by one cycle at $72^{\circ} \mathrm{C}$ for 30 minutes. The

140 products were visualised on a gel and then genotyped using an $A B I$ sequencer. Positive control

141 samples were added to each plate genotyped to account for possible allele slippage.

142 Genotypes were scored using GeneMapper@ v4.1 (Applied Biosystems) and validated through

143 Microchecker (van Oosterhout et al., 2004). Duplicates were found between the two batches using

144 CERVUS (Marshall et al., 1998). In cases where some alleles within the genotype did not match,

145 controls were used as a reference to identify possible allele slippage. Probabilities of the identity

146 analysis (pID) were taken from CERVUS to confirm match identification between the two batches.

\subsection{Danio rerio and Dicentrarchus labrax re-analysis}

149 The computational analysis pipeline (sections 2.5-2.7 below) was also implemented on previously

150 published RNA-seq datasets of temperature-induced developmental programming in zebrafish ( $D$.

151 rerio) hypaxial fast muscle (Scott \& Johnston, 2012) and European seabass (D. labrax) muscle tissue

152 (Anastasiadi et al., 2021, Anastasiadi \& Piferrer, 2019). This analysis was performed to assess the

153 robustness and between-species consistency of the temperature-induced effects observed in $S$.

154 canicula. 
155 Full details of the animals used in the re-analysis can be found in Scott \& Johnston 2012 (D. rerio, age = 8-9 months, $\mathrm{N}=5-8)$ and Anastasiadi et al. 2021 and Anastasiadi \& Piferrer, 2019 (D. labrax, age $=36$ months, $N=5$ ) respectively. The $D$. rerio and $D$. labrax data were processed in an identical manner to the $S$. canicula data. Transcriptome assembly statistics for the three species are shown in table 1.

\section{5 de-novo transcriptome assembly and differential expression analysis}

162

163

164

165

166

167

168

169

170

171

172

173

174

175

176

177

178

179

180

181

182

183

184

185

186

187

188

189

190

191

192

The ventricle tissue from six individuals ( $N=3$ per treatment group), stored in RNAlater at $-80^{\circ} \mathrm{C}$, was used for generating the transcriptome. The tissue samples were extracted using the Qiagen kit with homogenisation. Basic sample quality was assessed using a Nanodrop (ThermoFisher) and the highquality ventricular RNA samples were sequenced using a 76 base pair long, pair-ended reads on the Illumina TruSeq system. Reads that mapped to human, bacterial, and viral sequences were removed using DeconSeq (Schmieder and Edwards, 2011) whilst reads mapping to ribosomal RNA were removed using sortmeRNA (Kopylova et al., 2012). Adaptor sequences and sequences with a lowquality score (regions averaging a score $<5$ over a $4 \mathrm{bp}$ sliding window, and leading/trailing sequences scoring $<5$ ) were then removed from the cleaned reads using Trimmomatic (Bolger et al., 2014) prior to transcriptome assembly. 264 million bases survived the quality control process and were used for transcriptome assembly in Trinity 2.8.4 (Grabherr et al., 2011; Haas et al., 2013). Default parameters were used in Trinity, except -normalize_reads, producing 347710 contigs with a N50 of 1422, and a BUSCO score of $88.8 \%$, with 519 single copy, and 2458 duplicated copy, BUSCOs (BUSCO v5.2.2, Simao et al., 2015). Open reading frames (ORFs) were predicted from the transcripts using Transdecoder (https://github.com/TransDecoder/TransDecoder/wiki) with a minimum length threshold of 100 amino acids. The retained predicted protein sequences were annotated using a BLAST search against the SwissProt database. The quality-controlled reads were then mapped using Bowtie-2 (Langmead \& Salzberg, 2012), and pseudo-aligned to the de novo transcript assemblies using Kallisto (Bray et al., 2016), allowing the relative abundance of each gene to be calculated. Where multiple transcripts mapped to a single predicted protein, the median transcript abundance was used. The abundance estimates were filtered by removing fragments that had zero mapped reads in any of the samples before differential expression analysis was performed with EdgeR (McCarthy et al., 2012; Robinson et al., 2010) in R 3.6.0 (R core team, 2019).

\subsection{Hypernetwork analysis}

The differentially expressed genes (DEGs) were then used for hypernetwork analysis to assess the network properties of the transcriptomes from the $15^{\circ} \mathrm{C}$ and $20^{\circ} \mathrm{C}$ treatment groups (supplementary figure 1). The expression of each DEG was tested for correlations against all the assembled transcripts within each treatment group. The correlation values were binarized using a cut-off of one standard deviation from the mean, such that strong positive or negative correlations were retained (denoted as 1) and weak correlations were discarded (denoted as 0 ). The binarized correlation matrix is square (DEGs $x$ DEGs) and represents the incidence matrix of the hypernetwork. The binarized 
correlation matrix was then multiplied by the transpose of itself $\left(M * M^{t}\right)$ to return the adjacency matrix of the hypernetwork, where the values in each cell represent the number of correlations with nonDEGs shared between any pair of DEGs. These values also represent the dimensionality of the hyperedge connecting each pair of nodes. Supplementary figure 1 gives an overview of the hypernetwork analysis. The data were visualised as heatmaps to assess clustering of the genes, pergene connectivity, and per-gene Shannon entropy (herein, entropy) using the R packages mixOmics (Rohart et al., 2017) and BioQC (Zhang et al., 2017). A highly connected, central cluster of genes was identified using hierarchical clustering on each heatmap and the connectivity and entropy of the genes in these clusters was calculated. Connectivity was calculated for each gene as the sum of shared connections made between the given gene and all other DEGs in the hypernetwork. Entropy per-gene was calculated with the same values in a column-by-column manner using BioQC (Zhang et al., 2017) in R 3.6.0 (R core team, 2019), and scaled to size of the central cluster by taking $\log _{2} N^{2}$, where $\mathrm{N}$ is the length of the gene list.

Having identified differences in the connectivity and entropy of the hypernetwork models of DEG interactions, we extended this approach to assess the gene network properties across the whole transcriptome. To do this, we selected a random set of non-differentially expressed genes $(N=160$, to match the size of the DEGs list) and subjected them to the hypernetwork analysis described above. Entropy and connectivity were calculated on the central cluster genes per iteration, and entropy scores were then scaled to gene list size by taking $\log _{2} N^{2}$, where $\mathrm{N}$ is the length of the gene list. This hypernetwork approach was iterated 10,000 times to provide a whole-transcriptome assessment of connectivity and entropy for animals from each treatment group. Wilcoxon tests were used to contrast entropy and connectivity between the sharks incubated at $15^{\circ} \mathrm{C}$ and $20^{\circ} \mathrm{C}$.

\subsection{Over-representation analysis on the central cluster of transcriptional activity}

Having generated the hypernetwork adjacency matrices from the DEGs, hierarchical clustering was used and identified a group of highly connected genes present in the $15^{\circ} \mathrm{C}$, but not $20^{\circ} \mathrm{C}$, incubated sharks. This refined set of DEGs share the largest number of correlations across the rest of the transcriptome and as such, the expression patterns of these genes are related. We identified the highly connected genes present in the cold incubated animals (yellow clusters, fig. 2a, 2c \& 2e) and subtracted the few highly connected genes from the warm-incubated animals (yellow clusters, fig. $2 b$, $2 \mathrm{~d} \& 2 \mathrm{f}$ ). This final per-species gene list represents the genes whose highly connected nature with the transcriptome is disrupted by elevated incubated temperature. Over representation analysis was performed on these genes in DAVID, using each species' full gene list as a reference, to predict possible biological function (Huang et al., 2009a; Huang et al., 2009b).

\section{RESULTS}

The expression of 160 genes in the ventricle of $S$. canicula, 125 genes from D. rerio muscle, and 341 from $D$. labrax muscle tissue, were significantly altered by temperature during embryogenesis $(S$. canicula: 90 upregulated and 70 downregulated, $p$-value range $=1 \times 10^{-3}-3.3 \times 10^{-17}$; Danio rerio: 112 
231 upregulated, 13 downregulated, $p$-value range $=1 \times 10^{-3}-7.2 \times 10^{-7}$; Dicentrarchus labrax: 293

232 upregulated and 48 downregulated, $p$-value range $\left.=1 \times 10^{-3}-9.56 \times 10^{-11}\right)$.

234

235
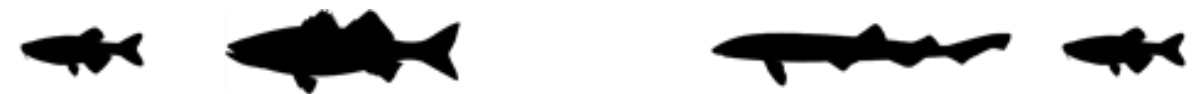

(a)
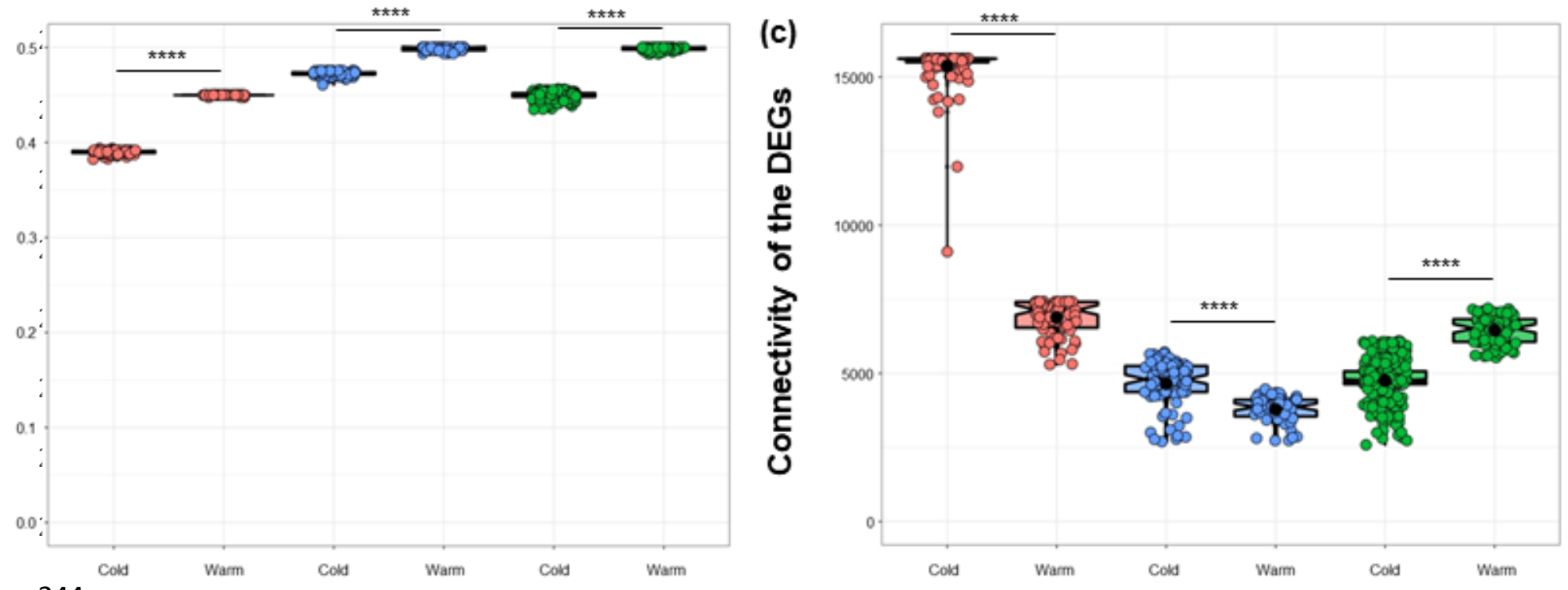

(b)

.

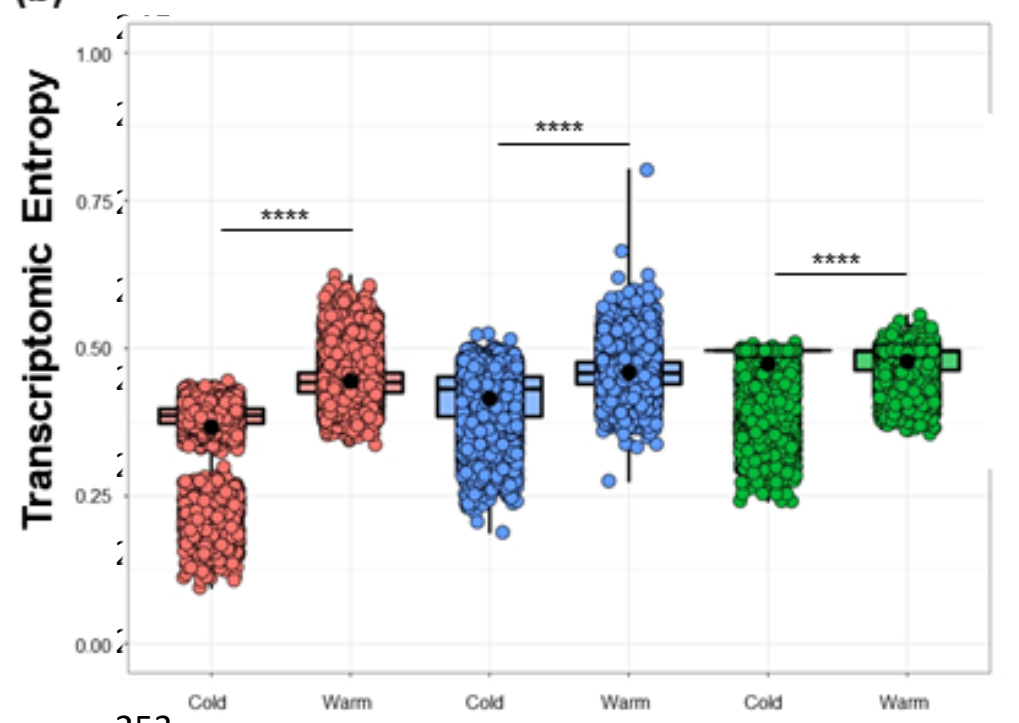

(d)

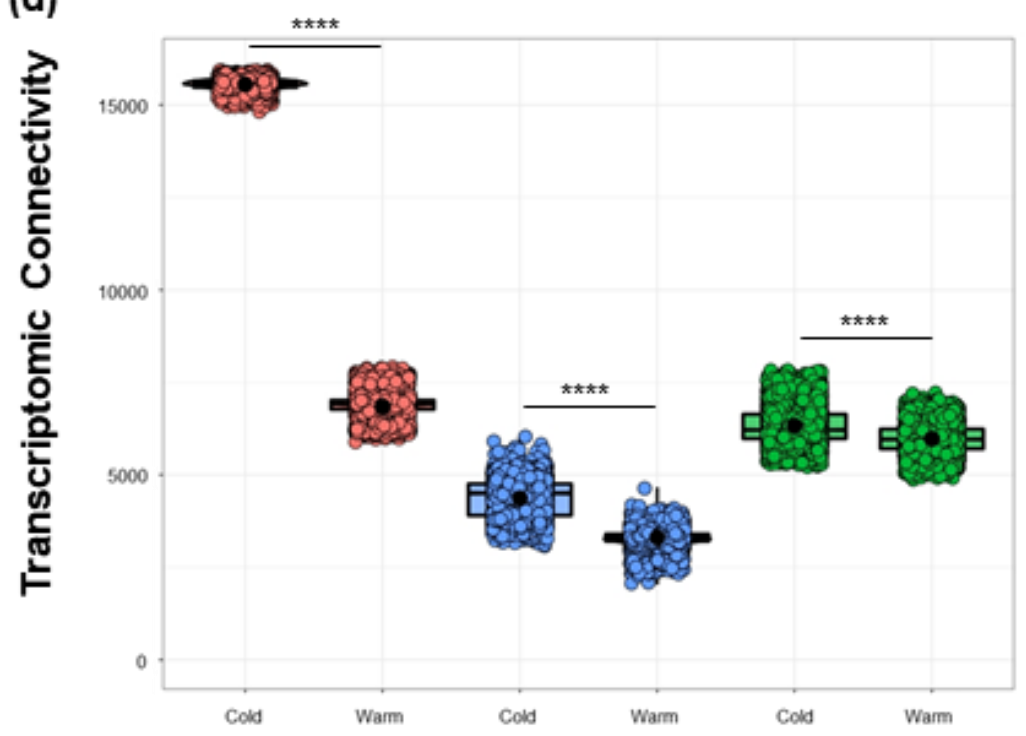

254

256

256

257

FIGURE 1 The entropy ( $A$ \& $C$ ) and connectivity (B \& D) of the differentially expressed genes ( $\&$ \& B) and entire transcriptome ( $C \& D$ ) of Scyliorhinus canicula (red, $N=3$ ), Danio rerio (green, $N=5-8$ ), and Dicentrarchus labrax (blue, $\mathrm{N}=5$ ) that experienced embryogenesis at different temperatures. Asterisks denote statistically significant differences between temperature treatment groups (Wilcoxon test; ${ }^{*} p \leq$ $0.05,{ }^{* *} p \leq 0.01,{ }^{* * *} p \leq 0.001,{ }^{* * *} p \leq 0.0001$ ). 
Hypernetwork analysis was performed on both the DEGs lists identified in each species, and on 10,000 permuted random subsets of the entire transcriptome. Embryogenesis at an elevated temperature significantly increased the entropy (Figure 1a; S. canicula $p<2.2 \times 10^{-16}, D$. rerio $p<$ $2.2 \times 10^{-16}, D$. labrax $\mathrm{p}<2.2 \times 10^{-16}$ ) of the DEGs in all three species, as well as reducing connectivity in $S$. canicula and $D$. rerio, whilst increasing it in $D$. labrax (Figure $1 \mathrm{~b}$; $S$. canicula $\mathrm{p}<2.2 \times 10^{-16}, D$. rerio $\mathrm{p}=4.8 \times 10^{-12}$

$$
\text { D. labrax } \mathrm{p}=2.2 \times 10^{-16} \text { ) }
$$

Connectivity was decreased in all three species across the entire transcriptome by an elevated incubation temperature (Figure 1d; S. canicula $\mathrm{p}<2.2 \times 10^{-16}$, D. rerio, $\mathrm{p}<2.2 \times 10^{-16}, D$. labrax $\mathrm{p}<$ $\left.2.2 \times 10^{-16}\right)$. However, entropy of the entire transcriptome was only increased in $S$. canicula and $D$. rerio, whilst the $D$. labrax transcriptome displayed a lower entropy following incubation at an elevated temperature (Figure 1c; $S$. canicula $\mathrm{p}<2.2 \times 10^{-16}$, D. rerio, $\mathrm{p}<2.2 \times 10^{-16}, D$. labrax $\mathrm{p}<2.2 \times 10^{-16}$ ). Scyliorhinus canicula, D. rerio, and D. labrax all had a clear cluster of highly connected DEGs (yellow clusters), when raised under control conditions (Figure 2a, c, e), which was not present in the animals raised at an elevated temperature (Figure $2 b, d, f$ ). Over-representation analysis of the genes present in these highly connected clusters highlighted a role for these genes in development and muscle contractile performance (Tables 2, 3 \& 4), amongst other processes. 
bioRxiv preprint doi: https://doi.org/10.1101/2021.12.07.470713; this version posted December 8, 2021. The copyright holder for this

preprint (which was not certified by peer review) is the author/funder, who has granted bioRxiv a license to display the preprint in perpetuity. It is made available under aCC-BY-ND 4.0 International license.

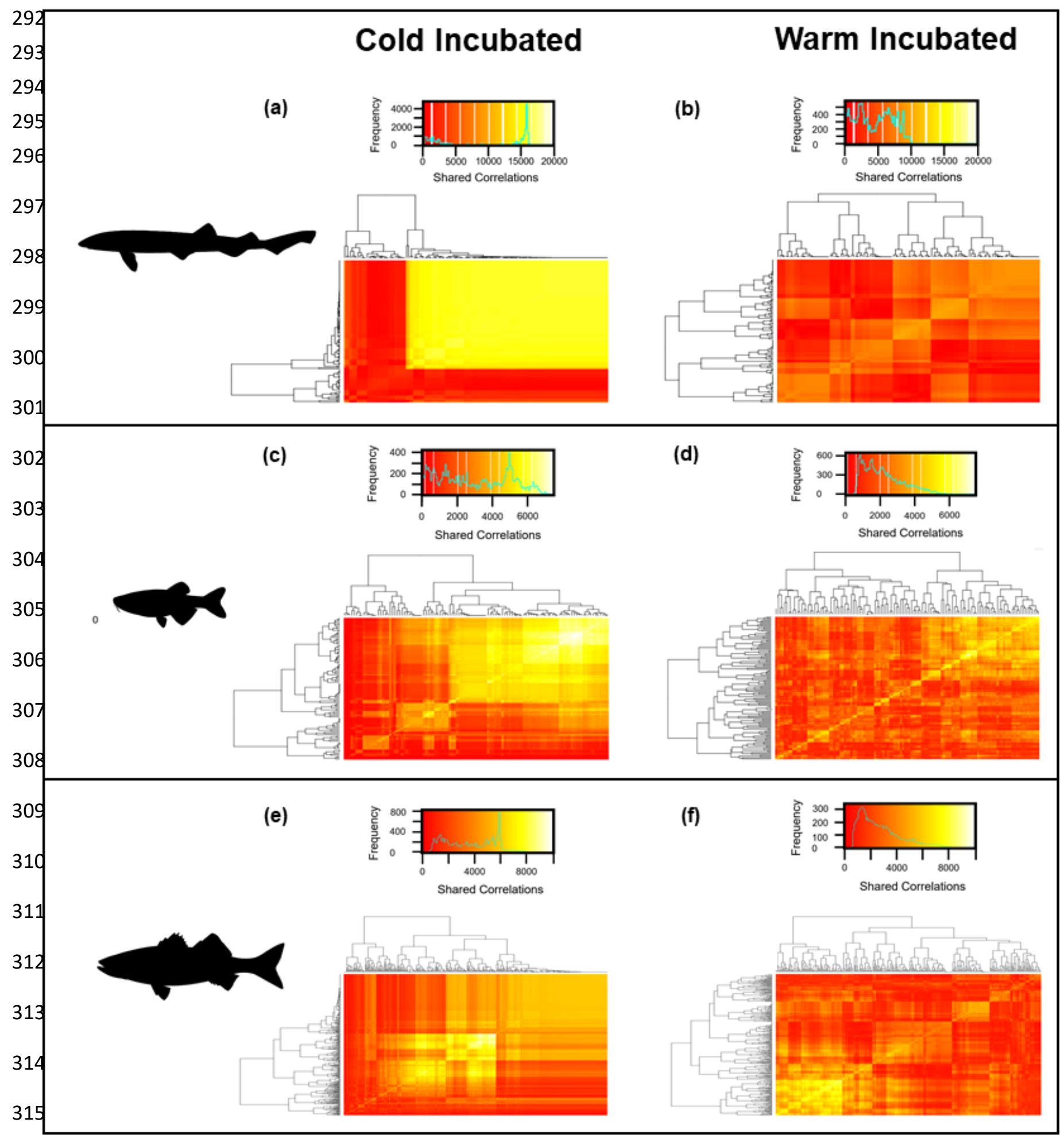

FIGURE 2 Heatmaps displaying the shared correlations between pairs of differentially expressed

317 genes to the rest of the transcriptome in Scyliorhinus canicula $(A \& B, N=3)$, Danio rerio $(C \& D, N=$ $5-8)$, and Dicentrarchus labrax $(E \& F, N=5)$ that experienced embryogenesis at either control $(A, C$,

E) or elevated temperature (B, D, F) conditions. The colour key, and a histogram of the data, are shown in the insets above each heatmap. 


\section{DISCUSSION}

322 Previous studies have shown that the thermal environment experienced during embryogenesis can

323 have persistent effects on the physiology, gene expression, and phenotypic plasticity of fishes

324 (Anastasiadi et al., 2021; Beaman et al., 2016; Schnurr et al., 2014; Scott \& Johnston, 2012). Here,

325 we show that elevated embryonic temperature also programs lasting changes to the organisation of

326 transcriptional networks in small-spotted catsharks (S. canicula), zebrafish (D. rerio), and European

327 seabass ( $D$. labrax), and suggest that this may play a role in the previously observed phenomena of

328 developmentally programmed, temperature-induced changes in phenotypic plasticity (Beaman et al.,

329 2016). Development at an elevated temperature resulted in differentially expressed genes (DEGs)

330 with a significantly higher entropy, and altered connectivity, in all three species. The properties of the

331 entire transcriptome were also significantly affected by developmental temperature. Transcriptome

332 wide gene connectivity was significantly decreased by an elevated incubation temperature in all three

333 species. Network entropy increased with developmental temperature in $S$. canicula and $D$. rerio, but

334 decreased marginally in $D$. labrax. The magnitude of this change was greatest in $S$. canicula, followed

335 by $D$. rerio, and then $D$. labrax. Interestingly, this order of effect sizes matches the times since

336 exposure, which were 4-5, 8-9, and 34 months in S. canicula, D. rerio, and D. labrax, respectively.

337 Whilst the DEGs identified in each species/tissue type showed little overlap, warming during

338 embryogenesis produced consistent effects on the properties of both the DEG and transcriptome-

339 wide gene networks. Such tissue independent transcriptomic signatures have been demonstrated

340 during growth in mammals (Stevens et al., 2013), and may relate to warming-induced changes in

341 ectotherm early-life growth pattern (Musa et al., 2020; Hume, 2019). These developmentally

342 programmed changes in transcriptional entropy and connectivity will change the response of the

343 transcriptome to future environmental challenges, which may result in altered phenotypic plasticity,

344 and thus may have implications for both physiological and population-level resilience to future

345 warming events.

346 Changes in the role of the DEGs in the transcriptional network, which manifest as an increase in

347 entropy and changes in connectivity, may consequently alter the ability of these genes and thus the

348 animal to mount a co-ordinated response to future environmental challenges. Recent studies have

349 suggested that the developmental environment influences the capacity to acclimate to environmental

350 changes in later-life (Beaman et al., 2016). For example, intertidal copepods (Tigriopus californicus)

351 that undergo embryogenesis at $25^{\circ} \mathrm{C}$ have the capacity to raise their critical thermal maximum as

352 adults through temperature acclimation (Healy et al., 2019). However, embryos of the same species

353 incubated at $20^{\circ} \mathrm{C}$ show no acclimation capacity in critical thermal maximum as adults (Healy et al.,

354 2019). Given that phenotypic plasticity is facilitated by co-ordinated changes in gene expression,

355 these developmentally programmed changes in phenotypic plasticity may relate to the changes in

356 transcriptional organisation observed in our study. Further studies support the link between embryonic

357 temperature and later-life acclimation capacity. Mosquitofish (Gambusia holbrooki) produce multiple

358 generations per year, with those born in summer experiencing a warm but constant environment, and 
bioRxiv preprint doi: https://doi.org/10.1101/2021.12.07.470713; this version posted December 8,2021 . The copyright holder for this preprint (which was not certified by peer review) is the author/funder, who has granted bioRxiv a license to display the preprint in perpetuity. It is made available under aCC-BY-ND 4.0 International license.

those born in spring experiencing cool, but steadily warming, conditions. Recent work has demonstrated that mosquitofish born in the more thermally variable spring environment have a greater capacity to acclimate their metabolic processes than mosquitofish from the more thermally stable summer conditions (Seebacher et al., 2014). Finally, studies of fruit flies (Drosophila melanogaster) have shown that heat tolerance is influenced not just by acclimation temperature, but by an interaction between acclimation temperature and embryonic temperature, further supporting the role of the early-life thermal environment in dictating an individual's response to future temperature challenges (Willot et al., 2021).

Studies of developmental programming resulting from environmental challenges in fish and reptiles have demonstrated a protective phenotype in later-life, in contrast to the negative effects often reported in mammals (Galli et al., 2021; Hellgren et al., 2021; Ruhr et al., 2019; Seeabacher et al., 2014). For example, work on the common snapping turtle (Chelydra serpentina) revealed that hypoxia exposure (50\% air saturation) throughout embryogenesis improved the anoxia tolerance of the cardiomyocytes isolated from juveniles (Ruhr et al., 2019). Similarly, jacky dragons (Amphibolurus muricatus) raised with extended basking times (11 vs. 7 hours of daily heat lamp exposure) show a higher panting threshold than those from control conditions, implying a greater thermal tolerance (So \& Schwanz, 2018). Such protective phenotypes, programmed by environmental challenges during embryogenesis, may be associated with the altered transcriptional landscape resulting from environmental stresses during early life. However, exposure to a stressor during embryogenesis does not always facilitate resilience to that stressor in adulthood. Cuban brown anole (Anolis sagrei) eggs incubated under cool, warm, and hot temperature fluctuations, and then raised in standard conditions after hatching, show no differences in thermal tolerance as adults (Gunderson et al., 2020). Thus, whilst developmental exposure to a stressor often influences the capacity to respond to that same stressor in later-life, it is not always the case.

One mechanism linking the developmental environment to later-life acclimation capacity is through the activity of DNA-methyltransferases (DNMTs) (Radford, 2018). DNA methylation by DNMTs can repress gene expression either directly, whereby the methylation prevents the interaction between a gene and its DNA binding proteins (Watt \& Molloy, 1988), or indirectly, through recognition of the methyl cytosine by methyl cytosine binding proteins, and the consequent recruitment of transcriptional corepressors (Boyes \& Bird, 1991; Klose \& Bird, 2006). Through these mechanisms, DNMTs can alter gene expression. Changes in embryonic temperature have been shown to alter DNA methylation patterns in fish (Metzger \& Schulte, 2017), with a recent study identifying DNMT3a as the mediator of developmental thermal plasticity in zebrafish (Danio rerio) (Loughland et al., 2021). Thus, by modulating DNMT3a's activity, changes in embryonic temperature can have persistent effects on the gene expression and plasticity of fishes (Loughland et al., 2021; Metzger \& Schulte, 2017). Whilst the DEGs identified in our study show little overlap between the species/tissue-types ( $S$. canicula; ventricle, table 2; $D$. rerio, hypaxial fast muscle, table 3 ; and $D$. labrax, muscle, table 4 ), the observed changes in entropy and connectivity span the entire transcriptome. This transcriptome-wide remodelling suggests that a mechanism basal to gene expression, such as DNA/chromatin 
398

399

400

401

402

403

404

405

406

407

408

409

410

411

412

413

414

415

416

417

418

419

420

421

422

423

424

425

426

427

428

429

430

431

432

433

434

methylation, may be facilitating the developmentally programmed changes in gene network coordination.

As well as implications for an organism's plasticity, changes in transcriptional entropy are known to be a predictor of biological fitness (Zhu et al., 2020). As stress increases, gene expression patterns become more random and consequently transcriptional entropy increases (Zhu et al., 2020). The negative relationship between transcriptional entropy and fitness has been demonstrated in seven species of bacteria, across a range of contexts, and found to be robust (Zhu et al., 2020). Therefore, within this framework, the increase in entropy caused by developmental exposure to elevated temperature in fishes could be interpreted as a decline in fitness. Whilst this interpretation is tentative, given that the negative relationship between entropy and fitness has only presently been demonstrated in bacteria (Zhu et al., 2020), studies in animals have shown later-life fitness costs of increased embryonic temperatures. Drosophila subobscura incubated at elevated temperatures throughout juvenilehood show a lower reproductive performance as adults than those incubated in control conditions, regardless of the temperatures experienced during later-life (Santos et al., 2021). Therefore, the link between the embryonic environment and later-life fitness is present in ectotherms, and future studies should probe the potential importance of transcriptional entropy in mediating these effects.

Climate change is a major threat facing animals. As the world's oceans and rivers continue to warm (Cai et al., 2014; Oliver et al., 2018), the physiological and population-level stresses exerted upon fishes will continue to grow. Embryogenesis is a sensitive period in many animal's life histories, and the conditions experienced during embryonic development influence their growth, physiology, and behaviour throughout their life. Consequently, to develop a comprehensive appreciation of how fishes will respond to climate change stressors, it is crucial that we develop an understanding, and incorporate into predictive models, the role of developmental programming in dictating an organisms' physiology and capacity to respond to future environmental challenges.

\section{Acknowledgements}

We thank Vicky Taylor and the aquarist team in the Biological Services Facility at the University of Manchester for their assistance in animal husbandry and tissue sampling for the microsatellite analysis. We thank Mar Pineda and Pierre Delaroche for their dissection skills. We thank the aquarist team of the Ozeaneum, Stralsund for shark breeding. Finally, we acknowledge the assistance given by Research IT and the use of the Computational Shared Facility at The University of Manchester.

\section{Competing Interests}

We declare no competing interests. 


\section{$435 \quad$ Funding}

436 This work was supported by the Biotechnology and Biological Sciences Research Council Doctoral

437 Training Studentship to D.M.R, the Higher Education Innovation Fund through the University of

438 Manchester's Knowledge and Innovation Hub for Environmental Stability to H.A.S, and the pump 439 priming fund through the University of Manchester's Cardiovascular Division awarded to H.A.S, A.S, 440 and P.C.

\section{$442 \quad$ Author Contributions}

443 D.M.R co-ordinated the experiments, analysed the data, and drafted the manuscript. T.G contributed 444 to the code and analytical method development. S.A.H and A.V performed the microsatellite analysis, 445 and S.A.H identified the individual animals. B.G and T.M supplied Scyliorhinus canicula eggs. H.A.S, 446 P.C, and A.S conceived the study, secured funding, and reviewed and revised the manuscript. All 447 authors contributed to the manuscript and gave their approval for publication.

\section{Data Availability}

450 Data are available through NCBl's Gene Expression Omnibus (GEO, Edgar et al., 2002) at the GEO accession number GSE189976. 
TABLE 1 Experimental details and transcriptome assembly statistics for Scyliorhinus canicula, Danio rerio, and Dicentrarchus labrax.

Parameter Species

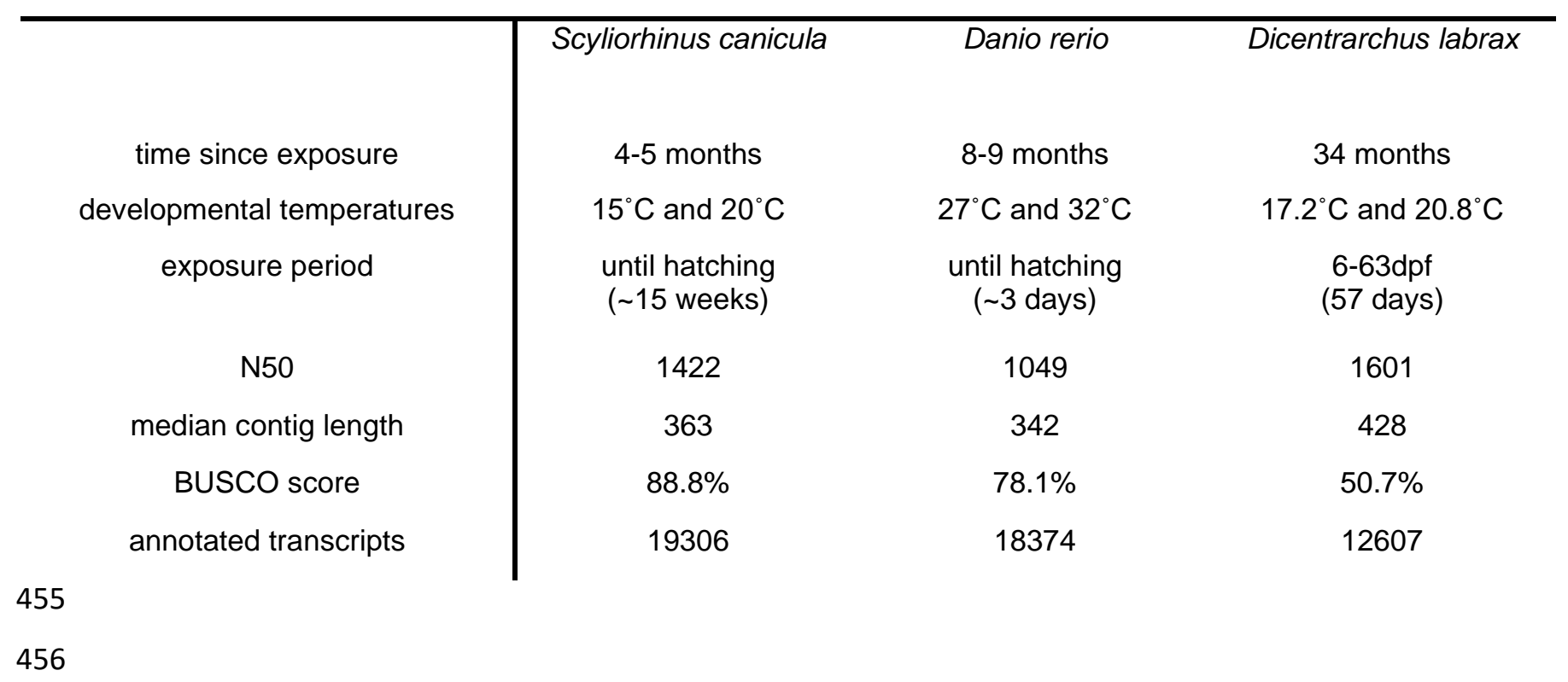

TABLE 2 Over-representation analysis of the differentially expressed genes identified in the central cluster of the cold, but not warm, incubated Scyliorhinus canicula

\begin{tabular}{l|c}
\multicolumn{1}{c|}{ Biological Process } & P-value \\
\hline multicellular organism development & 0.040 \\
response to tumour necrosis factor & 0.074 \\
gulation of telomere maintenance via telomerase & 0.092
\end{tabular}

457

458

459

460

461 
TABLE 3 Over-representation analysis of the differentially expressed genes identified in the central cluster of the cold, but not warm, incubated Danio rerio.

\begin{tabular}{c|c}
\hline Biological Process & P-value \\
\hline cellular response to UV & 0.061 \\
positive regulation of smooth muscle cell proliferation & 0.064 \\
negative regulation of apoptotic process & 0.069
\end{tabular}

467

468

469

470

471

472

473

TABLE 4 Top 10 results from over-representation of the differentially expressed genes identified in the central cluster of the cold, but not warm, incubated Dicentrarchus labrax.

\begin{tabular}{c|c}
\hline Biological Process & P-value \\
\hline ventricular cardiac muscle tissue morphogenesis & $4.4 \times 10^{-21}$ \\
muscle filament sliding & $1.7 \times 10^{-20}$ \\
regulation of the force of heart contraction & $2.0 \times 10^{-19}$ \\
cardiac muscle contraction & $4.6 \times 10^{-18}$ \\
transition between fast and slow fiber & $2.5 \times 10^{-15}$ \\
regulation of heart rate & $3.0 \times 10^{-14}$ \\
cardiac muscle hypertrophy in response to stress & $1.5 \times 10^{-12}$ \\
adult heart development & $9.8 \times 10^{-12}$ \\
skeletal muscle contraction & $2.7 \times 10^{-11}$ \\
ATP metabolic process & $5.4 \times 10^{-11}$
\end{tabular}



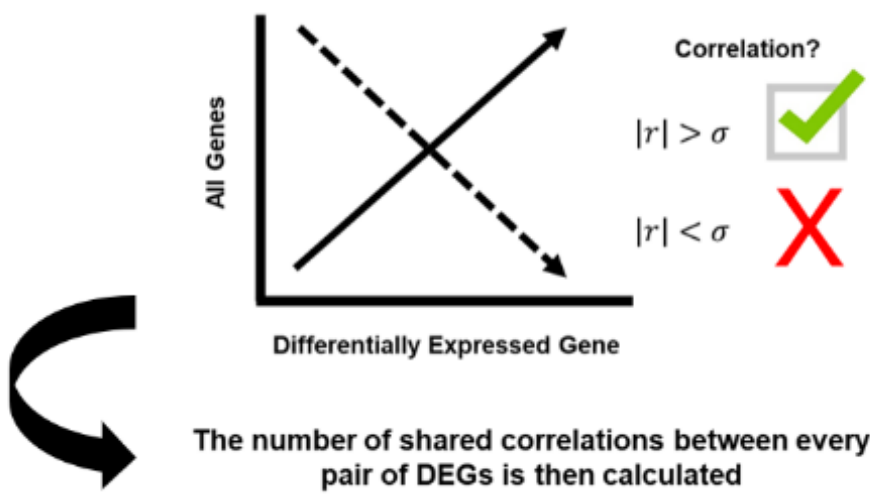

The number of shared correlations between every pair of DEGs is then calculated

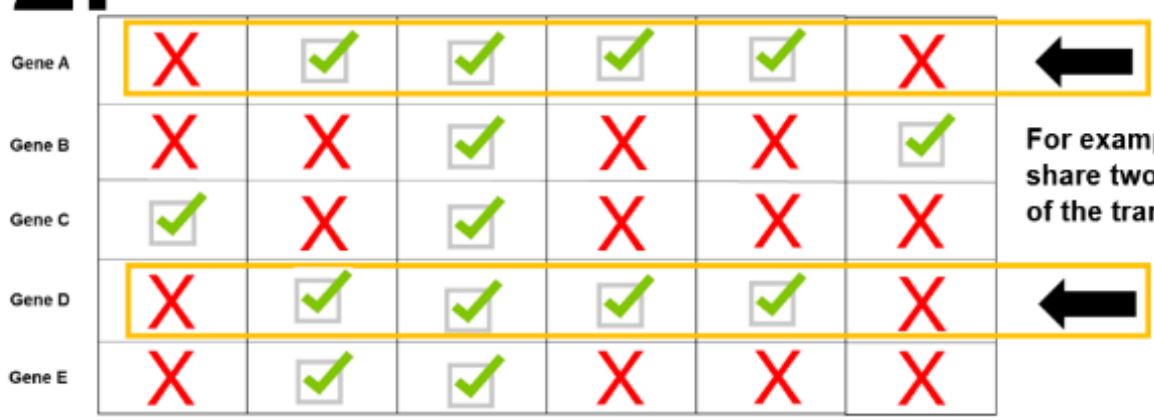

Supplementary Figure 1: A schematic qualitatively describing hypernetwork analysis. 1.) All the differentially

498 expressed genes (DEGs) identified between the two treatment groups are tested for correlations against all other genes identified within the transcriptome. The relationships are binarized as 1s (correlation) or 0s (no

499 correlation) based on a cut-off of one standard deviation. 2.) The number of correlations to the rest of the transcriptome that are shared between each possible pair of DEGs is calculated. In this, any pair of DEGs that

500 are correlated with many of the same genes will have a high shared correlations value, whilst any pair of DEGs that have no/few shared correlations will have a low shared correlations value. 3.) DEGs are

501 hierarchically clustered based on the similarity of their shared correlations allowing the identification of associated clusters of genes. This network can then be represented as a heatmap (Figure 2) and the

502 mathematical properties of the network (for instance, connectivity and entropy) can be calculated per treatment group. 
bioRxiv preprint doi: https://doi.org/10.1101/2021.12.07.470713; this version posted December 8,2021 . The copyright holder for this preprint (which was not certified by peer review) is the author/funder, who has granted bioRxiv a license to display the preprint in perpetuity. It is made available under aCC-BY-ND 4.0 International license.

\section{References}

Anastasiadi, D. \& Piferrer, F. (2019). 'Epimutations in developmental genes underlie the onset of domestication in farmed european sea bass' Molecular Biology and Evolution, 36 (10), pp. 2252-2264.

Anastasiadi, D., Shao, C. W., Chen, S. L. \& Piferrer, F. (2021). 'Footprints of global change in marine life: Inferring past environment based on DNA methylation and gene expression marks', Molecular Ecology, 30(3), pp. 747-760.

Banerji, C. R. S., Miranda-Saavedra, D., Severini, S., Widschwendter, M., Enver, T., Zhou, J. X. \& Teschendorff, A. E. (2013). 'Cellular network entropy as the energy potential in Waddington's differentiation landscape', Scientific Reports, 3.

Bateson, P., Gluckman, P. \& Hanson, M. (2014). 'The biology of developmental plasticity and the Predictive Adaptive Response hypothesis', Journal of Physiology-London, 592(11), pp. 23572368.

Beaman, J. E., White, C. R. \& Seebacher, F. (2016). 'Evolution of Plasticity: Mechanistic Link between Development and Reversible Acclimation', Trends in Ecology \& Evolution, 31(3), pp. 237-249.

Benjamins, S., Cole, G., Naylor, A., Thorburn, J. A. \& Dodd, J. 'First confirmed complete incubation of a flapper skate (Dipturus intermedius) egg in captivity', Journal of Fish Biology.

Bolger, A. M., Lohse, M. \& Usadel, B. (2014). 'Trimmomatic: a flexible trimmer for Illumina sequence data', Bioinformatics, 30(15), pp. 2114-2120.

Boyes, J. \& Bird, A. (1991). 'DNA METHYLATION INHIBITS TRANSCRIPTION INDIRECTLY VIA A METHYL-CPG BINDING-PROTEIN', Cell, 64(6), pp. 1123-1134.

Bray, N. L., Pimentel, H., Melsted, P. \& Pachter, L. (2016). 'Near-optimal probabilistic RNA-seq quantification', Nature Biotechnology, 34(5), pp. 525-527.

Cai OR, Poloczanska ES, Brewer PG, Sundby S, Hilmi K, Fabry VJ, Jung S (2014) The ocean in climate: change 2014: impacts, adaptation, and vulnerability. Part B: regional aspects. In VR Barros, CB Field, DJ Dokken, MD Mastrandrea, KJ Mach, TE Bilir, M Chatterjee, KL Ebi, YO Estrada, RC Genova et al., eds, Contribution of Working Group II to the Fifth Assessment Report of the Intergovernmental Panel on Climate Change. Cambridge University Press, Cambridge, United Kingdom and New York, NY, USA, pp. 1655-1731

Edgar, R., Domrachev, M. \& Lash, A. E. (2002). 'Gene expression omnibus: Ncbi gene expression and hybridization array data repository' Nucleic Acids Research, 30 (1), pp. 207-210. DOI: 10.1093/nar/30.1.207 Available at: <Go to ISI>://WOS:000173077100055

Fellous, A., Favrel, P. \& Riviere, G. (2015). 'Temperature influences histone methylation and mRNA expression of the $\mathrm{Jmj}-\mathrm{C}$ histone-demethylase orthologues during the early development of the oyster Crassostrea gigas', Marine Genomics, 19, pp. 23-30.

Galli, G. L. J., Ruhr, I. M., Crossley, J. \& Crossley, D. A. (2021). 'The Long-Term Effects of Developmental Hypoxia on Cardiac Mitochondrial Function in Snapping Turtles', Frontiers in Physiology, 12.

Geurden, I., Mennigen, J., Plagnes-Juan, E., Veron, V., Cerezo, T., Mazurais, D., ZamboninoInfante, J., Gatesoupe, J., Skiba-Cassy, S. \& Panserat, S. (2014). 'High or low dietary carbohydrate: protein ratios during first-feeding affect glucose metabolism and intestinal microbiota in juvenile rainbow trout', Journal of Experimental Biology, 217(19), pp. 33963406. 
bioRxiv preprint doi: https://doi.org/10.1101/2021.12.07.470713; this version posted December 8,2021 . The copyright holder for this preprint (which was not certified by peer review) is the author/funder, who has granted bioRxiv a license to display the preprint in perpetuity. It is made available under aCC-BY-ND 4.0 International license.

Grabherr, M. G., Haas, B. J., Yassour, M., Levin, J. Z., Thompson, D. A., Amit, I., Adiconis, X., Fan, L., Raychowdhury, R., Zeng, Q. D., Chen, Z. H., Mauceli, E., Hacohen, N., Gnirke, A., Rhind, N., di Palma, F., Birren, B. W., Nusbaum, C., Lindblad-Toh, K., Friedman, N. \& Regev, A. (2011). 'Full-length transcriptome assembly from RNA-Seq data without a reference genome', Nature Biotechnology, 29(7), pp. 644-U130.

Griffiths, A. M., Casane, D., McHugh, M., Wearmouth, V. J., Sims, D. W. \& Genner, M. J. (2011). 'Characterisation of polymorphic microsatellite loci in the small-spotted catshark (Scyliorhinus canicula L.)', Conservation Genetics Resources, 3(4), pp. 705-709.

Gunderson AR, Fargevieille A, Warner DA. 2020 Egg incubation temperature does not influence adult heat tolerance in the lizard Anolis sagrei. Biol. Lett. 16: 20190716. http://dx.doi.org/10.1098/rsbl.2019.0716

Haas, B. J., Papanicolaou, A., Yassour, M., Grabherr, M., Blood, P. D., Bowden, J., Couger, M. B., Eccles, D., Li, B., Lieber, M., MacManes, M. D., Ott, M., Orvis, J., Pochet, N., Strozzi, F., Weeks, N., Westerman, R., William, T., Dewey, C. N., Henschel, R., Leduc, R. D., Friedman, N. \& Regev, A. (2013). 'De novo transcript sequence reconstruction from RNA-seq using the Trinity platform for reference generation and analysis', Nature Protocols, 8(8), pp. 14941512.

Healy, T. M., Bock, A. K. \& Burton, R. S. (2019). 'Variation in developmental temperature alters adulthood plasticity of thermal tolerance in Tigriopus californicus', Journal of Experimental Biology, 222(22).

Hellgren, K. T., Premanandhan, H., Quinn, C. J., Trafford, A. W. \& Galli, G. L. J. (2021). 'Sexdependent effects of developmental hypoxia on cardiac mitochondria from adult murine offspring', Free Radical Biology and Medicine, 162, pp. 490-499.

Hook, S. A., McMurray, C., Ripley, D. M., Allen, N., Moritz, T., Grunow, B. \& Shiels, H. A. (2019). 'Recognition software successfully aids the identification of individual small-spotted catsharks Scyliorhinus canicula during their first year of life', Journal of Fish Biology, 95(6), pp. $1465-1470$.

Huang, D. W., Sherman, B. T. \& Lempicki, R. A. (2009a). 'Bioinformatics enrichment tools: paths toward the comprehensive functional analysis of large gene lists', Nucleic Acids Research, 37(1), pp. 1-13.

Huang, D. W., Sherman, B. T. \& Lempicki, R. A. (2009b). 'Systematic and integrative analysis of large gene lists using DAVID bioinformatics resources', Nature Protocols, 4(1), pp. 44-57.

Hume, J. B. (2019). 'Higher temperatures increase developmental rate \& reduce body size at hatching in the small-eyed skate Raja microocellata: implications for exploitation of an elasmobranch in warming seas', Journal of Fish Biology, 95(2), pp. 655-658.

IPCC, 2021: Climate Change 2021: The Physical Science Basis. Contribution of Working Group I to the Sixth Assessment Report of the Intergovernmental Panel on Climate Change [MassonDelmotte, V., P. Zhai, A. Pirani, S.L. Connors, C. Péan, S. Berger, N. Caud, Y. Chen, L. Goldfarb, M.I. Gomis, M. Huang, K. Leitzell, E. Lonnoy, J.B.R. Matthews, T.K. Maycock, T. Waterfield, O. Yelekçi, R. Yu, and B. Zhou (eds.)]. Cambridge University Press. In Press.

Klose, R. J. \& Bird, A. P. (2006). 'Genomic DNA methylation: the mark and its mediators', Trends in Biochemical Sciences, 31(2), pp. 89-97.

Kopylova, E., Noe, L. \& Touzet, H. (2012). 'SortMeRNA: fast and accurate filtering of ribosomal RNAs in metatranscriptomic data', Bioinformatics, 28(24), pp. 3211-3217. 
Langmead, B. \& Salzberg, S. L. (2012). 'Fast gapped-read alignment with Bowtie 2', Nature Methods, 9(4), pp. 357-U54.

Liu, J. W., Dias, K., Plagnes-Juan, E., Veron, V., Panserat, S. \& Marandel, L. (2017). Long-term programming effect of embryonic hypoxia exposure and high-carbohydrate diet at first feeding on glucose metabolism in juvenile rainbow trout. Journal of Experimental Biology, 220(20), 3686-3694.

Loughland, I., Little, A. \& Seebacher, F. (2021). 'DNA methyltransferase 3a mediates developmental thermal plasticity', Bmc Biology, 19(1).

Marshall, T. C., Slate, J., Kruuk, L. E. B. \& Pemberton, J. M. (1998). 'Statistical confidence for likelihood-based paternity inference in natural populations', Molecular Ecology, 7(5), pp. 639655.

McCarthy, D. J., Chen, Y. S. \& Smyth, G. K. (2012). 'Differential expression analysis of multifactor RNA-Seq experiments with respect to biological variation', Nucleic Acids Research, 40(10), pp. 4288-4297.

McLaughlin, R. H. \& Ogower, A. K. (1971). 'LIFE-HISTORY AND UNDERWATER STUDIES OF A HETERODONT SHARK', Ecological Monographs, 41(4), pp. 271-+.

Metzger, D. C. H. \& Schulte, P. M. (2017). 'Persistent and plastic effects of temperature on DNA methylation across the genome of threespine stickleback (Gasterosteus aculeatus)', Proceedings of the Royal Society B-Biological Sciences, 284(1864).

Musa, S. M., Czachur, M. V. \& Shiels, H. A. (2018). 'Oviparous elasmobranch development inside the egg case in 7 key stages', Plos One, 13(11).

Musa, S. M., Ripley, D. M., Moritz, T. \& Shiels, H. A. (2020). 'Ocean warming and hypoxia affect embryonic growth,fitness and survival of small-spotted catsharks,Scyliorhinus canicula', Journal of Fish Biology, 97(1), pp. 257-264.

Oliver, E. C. J., Donat, M. G., Burrows, M. T., Moore, P. J., Smale, D. A., Alexander, L. V., Benthuysen, J. A., Feng, M., Sen Gupta, A., Hobday, A. J., Holbrook, N. J., PerkinsKirkpatrick, S. E., Scannell, H. A., Straub, S. C. \& Wernberg, T. (2018). 'Longer and more frequent marine heatwaves over the past century', Nature Communications, 9.

R Core Team (2019). R: A language and environment for statistical computing. R Foundation for Statistical Computing, Vienna, Austria. URL https://www.R-project.org/.

Radford, E. J. (2018). 'Exploring the extent and scope of epigenetic inheritance', Nature Reviews Endocrinology, 14(6), pp. 345-355.

Robinson, M. D., McCarthy, D. J. \& Smyth, G. K. (2010). 'edgeR: a Bioconductor package for differential expression analysis of digital gene expression data', Bioinformatics, 26(1), pp. 139-140.

Rohart, F., Gautier, B., Singh, A. \& Le Cao, K. A. (2017). 'mixOmics: An R package for 'omics feature selection and multiple data integration', Plos Computational Biology, 13(11).

Rosa, R., Baptista, M., Lopes, V. M., Pegado, M. R., Paula, J. R., Trubenbach, K., Leal, M. C., Calado, R. \& Repolho, T. (2014). 'Early-life exposure to climate change impairs tropical shark survival', Proceedings of the Royal Society B-Biological Sciences, 281(1793). 
bioRxiv preprint doi: https://doi.org/10.1101/2021.12.07.470713; this version posted December 8,2021 . The copyright holder for this preprint (which was not certified by peer review) is the author/funder, who has granted bioRxiv a license to display the preprint in perpetuity. It is made available under aCC-BY-ND 4.0 International license.

Ruhr, I. M., McCourty, H., Bajjig, A., Crossley, D. A., Shiels, H. A. \& Galli, G. L. J. (2019). 'Developmental plasticity of cardiac anoxia-tolerance in juvenile common snapping turtles (Chelydra serpentina)', Proceedings of the Royal Society B-Biological Sciences, 286(1905).

Santos, M. A., Carromeu-Santos, A., Quina, A. S., Santos, M., Matos, M. \& Simoes, P. (2021). 'High developmental temperature leads to low reproduction despite adult temperature', Journal of Thermal Biology, 95.

Schaefer, J. \& Ryan, A. (2006). 'Developmental plasticity in the thermal tolerance of zebrafish Danio rerio', Journal of Fish Biology, 69(3), pp. 722-734.

Schmieder, R. \& Edwards, R. (2011). 'Fast Identification and Removal of Sequence Contamination from Genomic and Metagenomic Datasets', Plos One, 6(3).

Schnurr, M. E., Yin, Y. \& Scott, G. R. (2014). 'Temperature during embryonic development has persistent effects on metabolic enzymes in the muscle of zebrafish', Journal of Experimental Biology, 217(8), pp. 1370-1380.

Scott, G. R. \& Johnston, I. A. (2012). 'Temperature during embryonic development has persistent effects on thermal acclimation capacity in zebrafish', Proceedings of the National Academy of Sciences of the United States of America, 109(35), pp. 14247-14252.

Seebacher, F., Beaman, J. \& Little, A. G. (2014). 'Regulation of thermal acclimation varies between generations of the short-lived mosquitofish that developed in different environmental conditions', Functional Ecology, 28(1), pp. 137-148.

Simao, F. A., Waterhouse, R. M., loannidis, P., Kriventseva, E. V. \& Zdobnov, E. M. (2015). 'BUSCO: assessing genome assembly and annotation completeness with single-copy orthologs', Bioinformatics, 31(19), pp. 3210-3212.

So, C. K. J. \& Schwanz, L. E. (2018). 'Thermal plasticity due to parental and early-life environments in the jacky dragon (Amphibolurus muricatus)', Journal of Experimental Zoology Part aEcological and Integrative Physiology, 329(6-7), pp. 308-316.

Stevens, A., Hanson, D., Whatmore, A., Destenaves, B., Chatelain, P. \& Clayton, P. (2013). 'Human growth is associated with distinct patterns of gene expression in evolutionarily conserved networks', Bmc Genomics, 14.

Teschendorff, A. E. \& Enver, T. (2017). 'Single-cell entropy for accurate estimation of differentiation potency from a cell's transcriptome', Nature Communications, 8.

Van Oosterhout, C., Hutchinson, W. F., Wills, D. P. M. \& Shipley, P. (2004). 'MICRO-CHECKER: software for identifying and correcting genotyping errors in microsatellite data', Molecular Ecology Notes, 4(3), pp. 535-538.

Watt, F. \& Molloy, P. L. (1988). 'CYTOSINE METHYLATION PREVENTS BINDING TO DNA OF A HELA-CELL TRANSCRIPTION FACTOR REQUIRED FOR OPTIMAL EXPRESSION OF THE ADENOVIRUS MAJOR LATE PROMOTER', Genes \& Development, 2(9), pp. 11361143.

Willot, Q., Ben, L. \& Terblanche, J. S. (2021). 'Interactions between developmental and adult acclimation have distinct consequences for heat tolerance and heat stress recovery', Journal of Experimental Biology, 224(16).

Zhang, J. T. D., Hatje, K., Sturm, G., Broger, C., Ebeling, M., Burtin, M., Terzi, F., Pomposiello, S. I. \& Badi, L. (2017). 'Detect tissue heterogeneity in gene expression data with BioQC', Bmc Genomics, 18. 
bioRxiv preprint doi: https://doi.org/10.1101/2021.12.07.470713; this version posted December 8, 2021. The copyright holder for this preprint (which was not certified by peer review) is the author/funder, who has granted bioRxiv a license to display the preprint in perpetuity. It is made available under aCC-BY-ND 4.0 International license.

Zhu, Z. Y., Surujon, D., Ortiz-Marquez, J. C., Huo, W. W., Isberg, R. R., Bento, J. \& van Opijnen, T. (2020). 'Entropy of a bacterial stress response is a generalizable predictor for fitness and antibiotic sensitivity', Nature Communications, 11(1). 